\title{
PENGEMBANGAN MODEL PERSEDIAAN ECONOMIC MANUFACTURING QUANTITY (EMQ) DENGAN PRODUK GANDA DAN STOCHASTIC
}

\author{
Sigit Susanto, S.T., M.T. \\ E-mail: sigits.kawandhasor@gmail.com \\ Program Studi Teknologi Pengolahan Karet dan Plastik, Politeknik ATK Yogyakarta \\ Jalan Ringroad Selatan Glugo Panggungharjo Sewon Bantul Yogyakarta 55188
}

Received: July 20, 2017; Accepted: October 31, 2017; Published: November 30, 2017

\begin{abstract}
In the current era of globalization, there is freedom of the flow of products that make the competition between companies become more stringent. In order to survive, PT. XYZ must perform its activities effectively and efficiently on all its parts. One of these lines is the warehouse or inventory line. The existing inventory system and run by PT $X Y Z$ is a production environment that produces more than one final product and the demand for its products is uncertain. Based on the condition of PT XYZ, the writer approached the existing inventory system at PT XYZ with inventory model of Economic Manufacturing Quantity, multi item, and probabilistic.
\end{abstract}

Keywords: Economic Manufacturing Quantity, Multi Item, Stochastic, Spreadsheet.

\begin{abstract}
ABSTRAK
Pada era globalisasi seperti sekarang ini, terjadi kebebasan arus produk sehingga membuat persaingan antar perusahaan menjadi semakin ketat. Agar dapat survive, perusahaan PT. XYZ harus melakukan kegiatannya secara efektif dan efisien pada semua lini bagiannya. Salah satu lini tersebut adalah lini gudang atau persediaan. Sistem persediaan yang ada dan dijalankan oleh PT XYZ merupakan lingkungan produksi yang memproduksi lebih dari satu produk akhir dan permintaan terhadap produknya tersebut tidak pasti. Berdasarkan kondisi PT XYZ tersebut, penulis mendekati system persediaan yang ada pada PT XYZ dengan model persediaan Economic Manufacturing Quantity, produk ganda, dan stochastic. Solusi terhadap model yang dibangun, diperoleh menggunakan bantuan spreadsheet.
\end{abstract}

Kata kunci: Economic Manufacturing Quantity, Produk Ganda, Stochastic, Spreadsheet 


\section{PENDAHULUAN}

Pendahuluan Agar suatu perusahaan tidak kehilangan konsumennya, suatu perusahaan memerlukan sistem pengendalian persediaan guna memenuhi permintaan konsumennya secara tepat baik dalam jenis, jumlah, kualitas, maupun waktunya.Dalam hal ini jika terjadi kekurangan persediaan akan menyebabkan tidak terpenuhinya permintaan pembeli dimana pada jangka panjang dapat menyebabkan kehilangan kepercayaan pembeli, sebaliknya jika terjadi persediaan yang berlebihan hal ini akan menyebabkan pembengkakan biaya simpan yang salah satunya dikarenakan kerusakan produk yang disimpan terlalu lama. PT XYZ merupakan perusahaan yang bergerak dalam memproduksi barang yaitu spiritus cair dan alcohol murni yang merupakan produk samping dari produk gula pasir (bukan jasa) sehingga pemodelan yang sesuai adalah model lingkungan produksi yang dapat didekati dengan model persediaan Economic Manufacturing Quantity (EMQ). Permintaan terhadap produk yang dihasilkan oleh PT. XYZ tidak dapat ditentukan dengan pasti, tetapi dapat diperkirakan menggunakan model kemungkinan atau biasa disebut dengan model stochastic. Di samping itu, PT. XYZ menghasilkan lebih dari satu produk atau dengan kata lain menghasilkan produk ganda. Dengan demikian, agar model yang dikembangkan mendekati kondisi riil PT. XYZ maka dikembangkan model persediaan Economic Manufacturing Quantity (EMQ) yang stochastic dengan produk ganda yang dapat dihasilkan melalu penggabungan antara model Economic Order Quantity (EOQ) stochastic dengan model persediaan Economic Manufacturing Quantity (EMQ) deterministik dengan analisis terhadap lebih dari satu produk. Berdasarkan latar belakang di atas, dapat disimpulkan bahwa rumusan masalah yang dihadapi perusahaan adalah sebagai berikut:
Berapakah jumlah produksi optimum (Q) dan tingkat ROP (Re-Order Point/titik pemesanan kembali) serta safety stock (S) yang harus dimilik untuk menghasilkan total biaya persediaan yang minimum pada kondisi yang probabilistik dan adanya stockout (terjadinya kekurangan persediaan) untuk setiap jenis produk menggunakan model persediaan yang sesuai?

Sedangkan tujuan yang ingin diperoleh dalam penelitian ini yaitu menentukan ukuran produksi ekonomis tiap jenis produk (Q) yaitu jumlah produk yang harus diproduksi untuk tiap jenis produk setiap kali dilakukan produksi dan menentukan reorder point (titik pemesanan kembali) tiap jenis produk (B) yaitu jumlah persediaan yang tersedia dimana dilakukan persiapan produksi untuk melakukan produksi tahap berikutnya yang meminimumkan total biaya persediaan dan menentukan persediaan pengaman/safety stock tiap jenis produk (S) yaitu persediaan untuk mengatasi ketidakpastian terhadap permintaan yang meminimumkan total biaya persediaan.

\subsection{Metodologi Penelitian}

Metodologi penelitian dilakukan dengan cara studi pustaka, observasi atau pengamatan pada PT. XYZ, dilanjutkan dengan identifikasi masalah di PT. XYZ dan dikembangkan solusi dengan menggunakan hasil studi pustaka. Metodologi penelitian tersebut ditunjukkan pada diagram alir penelitian pada Gambar 1.1 berikut ini: 


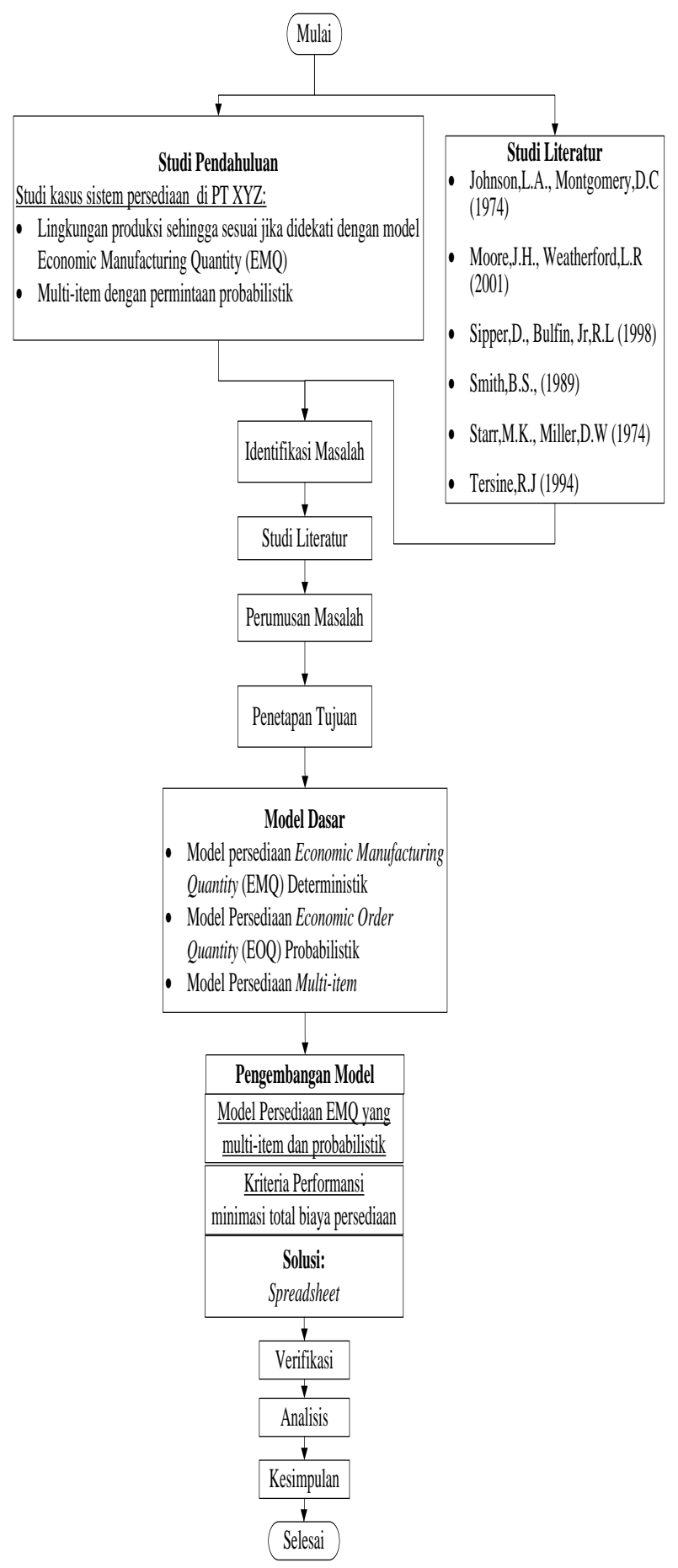

Gambar 1.1. Diagram Alir Penelitian

\subsection{Landasan Teori}

Daftar Notasi:

$R \quad=$ permintaan $($ demand $)$ tahunan
$P \quad=$ biaya pembelian per unit (untuk Model EOQ) atau biaya produksi per unit (untuk Model EMQ).

$C \quad=$ biaya pesan per pesan (untuk Model EOQ) atau biaya persiapan per persiapan produksi (untuk Model EMQ) $Q \quad=$ besarnya pesanan setiap pesan (untuk Model EOQ) atau besarnya produksi setiap produksi (untuk Model EMQ)

$Q^{*} \quad=$ besarnya pesanan ekonomis (untuk Model EOQ) atau besarnya produksi ekonomis (untuk Model EMQ)

$L \quad=$ lead time

$H \quad$ = biaya simpan per unit per tahun

$B \quad=$ reorder point (titik pemesanan

kembali)

$p \quad=$ Production rate (kecepatan

produksi)

$r \quad=$ Demand rate (kecepatan

permintaan)

$\mathrm{t}_{\mathrm{p}} \quad=$ Time to produce (waktu yang diperlukan untuk melakukan produksi)

$A \quad=$ biaya kekurangan per unit

$T C(Q) \quad=$ total biaya persediaan sebagai

fungsi $Q$

$S=$ safety stock $/$ persediaan

$\bar{M}=$ rata-rata permintaan saat lead time

$P(M>B)=$ probability of $a$ stockout/kemungkinan terjadinya kekurangan $P(s) \quad=$ probabilitas kekurangan yang optimum

$E(M>B) \quad=$ expected number of

stockout/jumlah kekurangan yang diharapkan 
$T C(Q, k) \quad=$ total biaya persediaan sebagai fungsi $Q$ dan $k$

$p_{u} \geq(k) \quad=$ probabilitas stockout

$\sigma_{L} \quad=$ standar deviasi permintaan saat

lead time

Menurut Johnson dan Montgomery (1974) terdapat fungsi khusus dari distribusi normal baku untuk mencari banyaknya stockout yang diharapkan sebagai berikut:

$$
\begin{array}{ll}
G_{u}(k) & =\text { fungsi khusus dari distribusi } \\
& \text { normal baku untuk mencari } \\
& \text { jumlah } \\
& \text { stockout yang diharapkan. } \\
& =\text { mean untuk Distribusi Normal } \\
\mu & =\text { varians untuk Distribusi } \\
\sigma^{2} & \\
\text { Normal } & \\
\bar{x} & =\text { rata-rata sampel } \\
s & =\text { standar deviasi sampel }
\end{array}
$$

Menurut Johnson and Montgomery (1974) terdapat model persediaan Economic Manufacturing Quantity sebagai berikut: 1.2.1. Model Persediaan Economic Manufacturing Quantity (EMQ) Deterministik.

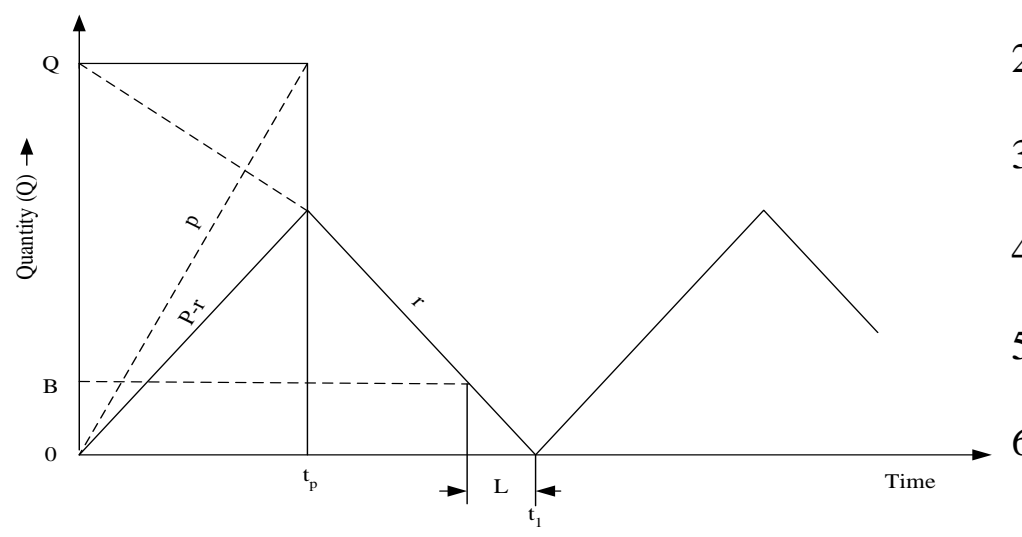

Gambar 1.2. Model EMQ Deterministik

Rumus:

Total Biaya Persediaan = Biaya Produksi + Biaya Persiapan + Biaya Simpan

$$
T C(Q)=P R+\frac{C R}{Q}+\frac{H Q(p-r)}{2 p}
$$

Jumlah produksi ekonomis,

$$
Q^{*}=\sqrt{\frac{2 C R p}{(H)(p-r)}}
$$

Reorder point produksi, $B=\frac{R L}{N}=r L$

Asumsi model di atas adalah sebagai berikut:

1. Constant Demand Rate (barang diambil dari persediaan dengan kecepatan permintaan yang tetap).

2. Constant Production Rate (kecepatan produksinya konstan).

3. Kecepatan produksinya lebih besar daripada kecepatan permintaannya.

4. Lead time diketahui dengan pasti dan konstan.

5. Tidak diijinkan terjadi stockout/kekurangan persediaan.

6. Noninstataneous receipt (penerimaan dalam barang ke dalam penyimpanan terjadi secara berangsur-angsur).

Menurut Tersine (1994) terdapat model persediaan Economic Order Quantity Stochastic sebagai berikut: 
1.2.2. Model EOQ Stochastic dengan Demand Variabel dan Lead Time Konstan.

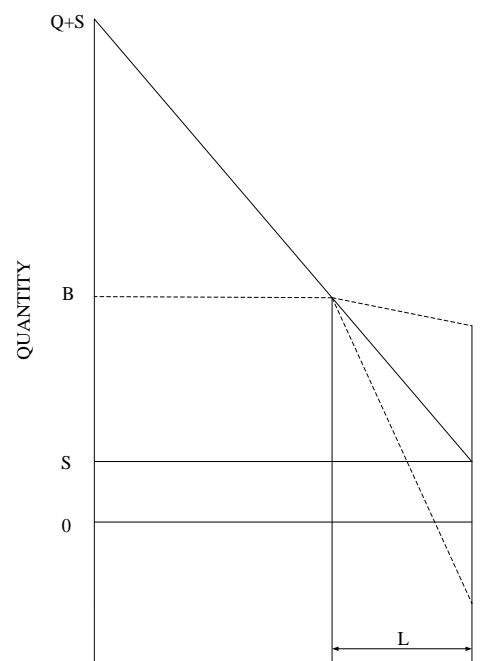

Gambar 1.3. Model EOQ Stochastic (demand variabel dan lead time konstan)

untuk kasus lost sales dengan biaya stockout per unit

Menurut Silver dan Bulfin (1998) terdapat pada kasus kekurangan persediaan terdapat dua kondisi yaitu lost sales (kehilangan penjualan dan tidak jadi mendapatkan keuntungan) dan kondisi backordered (permintaan dipenuhi pada periode berikutnya)

Rumus:

Total Biaya Persediaan = Biaya Pembelian + Biaya Tetap per Siklus (Biaya Pesan + Biaya Stockout) + Biaya Simpan

$\mathrm{TC}=$

$R P+\frac{R}{Q}[C+A \cdot E(M>B)]+H\left[\frac{Q}{2}+(B-\bar{M})+E(M>B)\right]$

$$
\begin{aligned}
& \text { Jumlah } \quad \text { pesanan } \\
& Q^{*}=\sqrt{\frac{2 R[C+A \cdot E(M>B)]}{H}}
\end{aligned}
$$

Probabilitas Stockout yang optimum,

$$
P(M>B)=P(s)=\frac{H Q}{A R+H Q}
$$

Menurut Silver dkk (1998), untuk data yang berdistribusi normal, total biaya persediaannya menjadi sebagai berikut:

$$
T C=R P+\frac{C R}{Q}+H\left\{\frac{Q}{2}+k \sigma_{L}\right\}+\frac{A \cdot \sigma_{L} \cdot G_{u}(k) \cdot R}{Q}
$$

\subsubsection{Convolution}

Menurut Walpole etal (1998) untuk data kurang dari 30 dapat dilakukan uji normalitas menggunakan uji Kolmogorov Smirnov. Setelah diketahui jenis distribusi permintaan yang dilakukan dengan uji Kolmogorov Smirnov, selanjutnya untuk mencari permintaan saat lead time, diperlukan convolution. Berikut ini merupakan convolution untuk permintaan yang berdistribusi normal.

Menurut Smith (1989), berdasarkan pada pertimbangan kemudahan sistem dan efisiensi dalam perhitungan, sering bahwa kasus distribusi permintaan diperkirakan dalam suatu interval waktu dasar seperti minggguan.

Pertimbangkan periode $n$ berikutnya, selama permintaan merupakan variabel acak $x_{1}, x_{2}, \ldots$, $x_{n}$. Rata-rata dan varian dari distribusi permintaan ini yaitu $\mu_{1}, \mu_{2}, \ldots, \mu_{2}$ dan $\sigma_{1}^{2}, \sigma_{2}{ }^{2}, \ldots, \sigma_{n}{ }^{2}$. Sekarang, pertimbangkan 
permintaan selama periode $\mathrm{n}$ yang akan menjadi $\mathrm{y}=x_{1}+x_{2}+\ldots+x_{n} \cdot y$ juga akan merupakan variable acak dan distribusinya disebut sebagai suatu convolution dari distribusi $x$.

Rata-rata dari distribusi $y$ adalah sebagai berikut:

$\mu_{y}=\mu_{1}+\mu_{2}+\ldots+\mu_{n}$

Jika distribusi $x$ semua mempunyai rata-rata yang sama, $\mu_{x}$, maka

$$
\mu_{y}=n \mu_{x}
$$

(2.22)

Sedangkan varian $y$ adalah sebagai berikut

$$
\sigma_{y}{ }^{2}=\sigma_{1}{ }^{2}+\sigma_{2}{ }^{2}+\ldots+\sigma_{n}{ }^{2}
$$

Sehingga, standar deviasi $y$ adalah sebagai berikut

$$
\sigma_{y}=\sqrt{\sigma_{1}^{2}+\sigma_{2}^{2}+\ldots+\sigma_{n}^{2}}
$$

Jika distribusi $x$ semuanya memiliki varian yang sama, $\sigma_{x}^{2}$, maka

$$
\sigma_{y}=\sqrt{n} \sigma_{x}
$$

\section{TINJAUAN PUSTAKA DAN PENGEMBANGAN HIPOTESIS}

Berdasarkan kondisi PT XYZ, terutama pada sistem persediaannya, penulis berusaha mendekati model persediaan PT XYZ dengan cara menggabungkan Model Persediaan Economic Manufacturing Quantity (EMQ) Deterministik dan Model EOQ Probabilistik (dengan Demand Variabel dan Lead Time Konstan) sehingga diperoleh model persediaan EMQ probabilistik.

2.1. Model EMQ Probabilistik (dengan Demand Variabel dan Lead time Konstan).

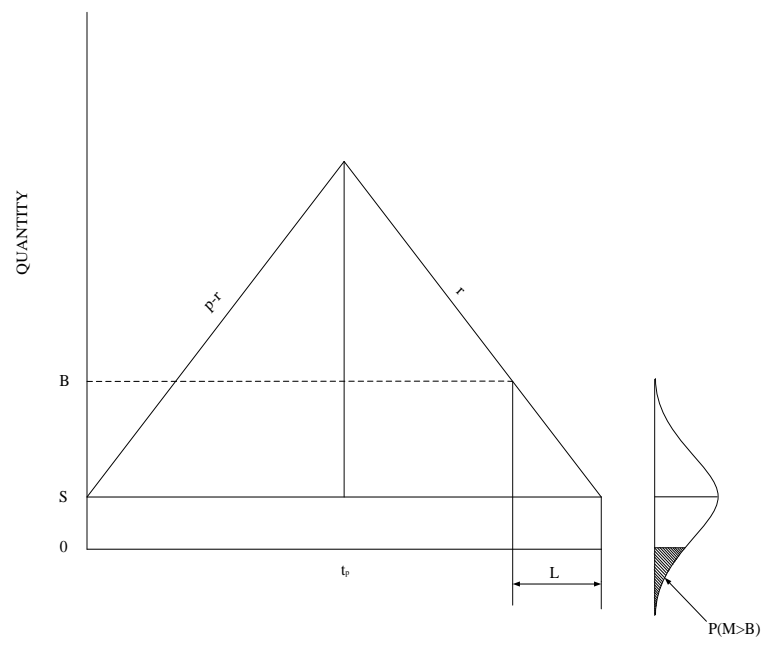

Gambar 1.4. . Model EMQ Probabilistik (variabel demand dan konstan lead time) untuk kasus lost sales dengan biaya stockout per unit

Menurut Smith (1989) total cost sebagai fungsi dari Q dan $\mathrm{k}$.

Rumus:

Total Biaya Persediaan = Biaya Persiapan

+ Biaya Produksi + Biaya Simpan

+ Biaya Kekurangan

$T C(Q, k)=\sum_{i=1}^{n} C \cdot \frac{R}{Q}+\sum_{i=1}^{n} P . R$

$+\sum_{i=1}^{n} H\left\{\frac{Q}{2} \cdot \frac{(p-r)}{p}+k \cdot \sigma_{L}\right\}+\sum_{i=1}^{n}\left\{\frac{A \cdot R}{Q}+H\right\} \cdot \sigma_{L} \cdot G_{u}(k)$

$(2.11)($

...(2.11)

Menurut Ayres etal (1992) dan Hsu (1997) untuk mendapatkan jumlah produksi yang optimum untuk setiap siklus produksi, dapat diperoleh dengan menurunkan Total Biaya Persediaan (TC) terhadap jumlah produksi (Q) dan menyamakannya dengan nol (0).

$\frac{\partial T C}{\partial Q}=\frac{\partial\left(C \cdot R \cdot Q^{-1}+\frac{H}{2} \cdot \frac{(p-r)}{p} \cdot Q+A \cdot R \cdot \sigma_{L} \cdot G_{u}(k) \cdot Q^{-1}\right)}{\partial Q}$ 


$$
Q=\sqrt{\frac{2}{H} \cdot \frac{p}{(p-r)} \cdot\left\{C \cdot R+A \cdot R \cdot G_{u}(k) \cdot \sigma_{L}\right\}}
$$

Dengan $\sigma_{L}=$ standar deviasi permintaan saat lead time

$$
\begin{aligned}
& \frac{d G_{u}(k)}{d k}=-p_{u} \geq(k) \\
& G_{u}(k) \sigma_{L}=\left\{f_{u}(k)-k \cdot p_{u} \geq(k)\right\} \cdot \sigma_{L}
\end{aligned}
$$

atau menurut Moore dan Weatherford (2001) dapat dicari dengan Microsoft Excel dengan rumus $G_{u}(k)=\{\operatorname{NORMDIST}(k ; 0 ; 1 ; 0)-k *(1-$ $\operatorname{NORMSDIST}(k))\} \sigma_{L}$

\section{(2.14)}

Probabilitas stockoutnya dapat diperoleh dengan menurunkan TC terhadap $\mathrm{k}$ dan menyamakannya dengan 0 (nol).

$$
\begin{aligned}
& \frac{\partial T C}{\partial k}=\frac{\partial\left(H \cdot \sigma_{L} \cdot k+\frac{A \cdot R}{Q} \cdot \sigma_{L} \cdot G_{u}(k)+H \cdot \sigma_{L} \cdot G_{u}(k)\right)}{\partial k} \\
& p_{u} \geq(k)=\frac{H \cdot Q}{A \cdot R+H \cdot Q} \\
& \ldots \ldots \ldots \ldots \ldots \ldots(2.15)
\end{aligned}
$$

Nilai $k$ dapat diperoleh melalui fungsi

$$
\text { inversnya, } k=p_{u}{ }^{-}\left(\frac{H \cdot Q}{A \cdot R+H \cdot Q}\right)
$$

atau dapat dicari dengan Microsoft Excel sebagai berikut:

$k=\operatorname{NORMSINV}\left(1-p_{u} \geq(k)\right)$

\section{HASIL DAN PEMBAHASAN}

Berikut ini merupakan Tabel 3.1 yang merupakan parameter beserta nilainya yang digunakan dalam menentukan total biaya persediaan tahunan. Indeks ke-1 merupakan parameter berserta nilainya untuk item ke-1,

\begin{tabular}{|c|c|c|c|c|}
\hline $\begin{array}{l}\mathbf{N} \\
\mathbf{0}\end{array}$ & $\begin{array}{c}\text { Notasi } \\
\text { item } \\
\text { ke-1 }\end{array}$ & Nilai & $\begin{array}{c}\text { Notasi } \\
\text { item } \\
\text { ke-2 } \\
\end{array}$ & Nilai \\
\hline 1 & $R_{1}$ & $\begin{array}{l}4.040 .880 \\
\text { (liter) }\end{array}$ & $R_{2}$ & $\begin{array}{l}3.434 .748 \\
\text { (liter) }\end{array}$ \\
\hline 2 & $\sigma_{y 1}$ & $\begin{array}{l}489.721 \\
\text { (liter) }\end{array}$ & $\sigma_{y 2}$ & $\begin{array}{l}416.263 \\
\text { (liter) }\end{array}$ \\
\hline 3 & $P_{1}$ & Rp3.350 & $P_{2}$ & Rp6.700 \\
\hline 4 & $H_{1}$ & Rp209 & $\mathrm{H}_{2}$ & Rp418 \\
\hline 5 & $A_{1}$ & Rp247 & $A_{2}$ & Rp494 \\
\hline 6 & $C_{1}$ & $\begin{array}{l}\text { Rp5.245. } \\
614\end{array}$ & $C_{2}$ & $\begin{array}{l}\text { Rp10.491. } \\
228\end{array}$ \\
\hline 7 & $L_{1}$ & $\begin{array}{l}0,0192 \\
\text { (tahun) }\end{array}$ & $L_{2}$ & $\begin{array}{l}0,0385 \\
\text { (tahun) }\end{array}$ \\
\hline 8 & $\frac{\left(p_{1}-r_{1}\right.}{p_{1}}$ & 0,2036 & $\frac{\left(p_{2}-r_{2}\right.}{p_{2}}$ & 0,6760 \\
\hline
\end{tabular}
sedangkan indeks ke-2 merupakan parameter beserta nilainya untuk item ke-2.

Tabel 3.1. Parameter beserta symbol \& Nilainya

Perhitungan selengkapnya dalam mendapatkan jumlah produksi optimal beserta total biaya persediaan tahunannya dapat dilihat pada Tabel 3.2 dan Tabel 3.3. Permasalahan PT XYZ didekati dengan Model Persediaan Economic Manufacturing Quantity (EMQ) stochastic yang diperoleh dengan penggabungan antara model Economic Order Quantity (EOQ) stochastic dengan Economic Manufacturing Quantity (EMQ) Deterministik. Sedangkan kondisi PT. XYZ yang produk ganda didekati dengan sigma. Untuk mendapatkan total biaya persediaan tahunan semua produk yang ada pada perusahaan, maka dihitung total biaya persediaan tahunannya untuk semua produk, 
dari produk ke-i sampai dengan produk ke-n. Pada penelitian ini digunakan 2 (dua) produk yang ada pada PT XYZ untuk digunakan dalam perhitungan, seperti terlihat pada Tabel 3.2. dan Tabel 3.3. Untuk produk ke-1 ukuran produksi ekonomisnya sebesar 1.202.935 liter, reorder pointnya sebesar 134.573liter, persediaan pengamannya sebesar 56.863 liter. Sedangkan untuk produk ke-2 ukuran produksi ekonomisnya sebesar 505.039 liter, reorder pointnya sebesar 178.331.197 liter, persediaan pengamannya sebesar 178.265.144 liter. Untuk produk ke-1 yang berupa alcohol murni ukuran ekonomisnya lebih besar karena memang lebih banyak permintaan dan kegunaannya, sedangkan untuk produk ke-2 lebih sedikit karena memang lebih sedikit permintaan dan kegunaannya. 
Tabel 3.2. Perhitungan Total Biaya Persediaan Tahunan untuk produk ke-1. Model EMQ Stochastic untuk Produk ke-1

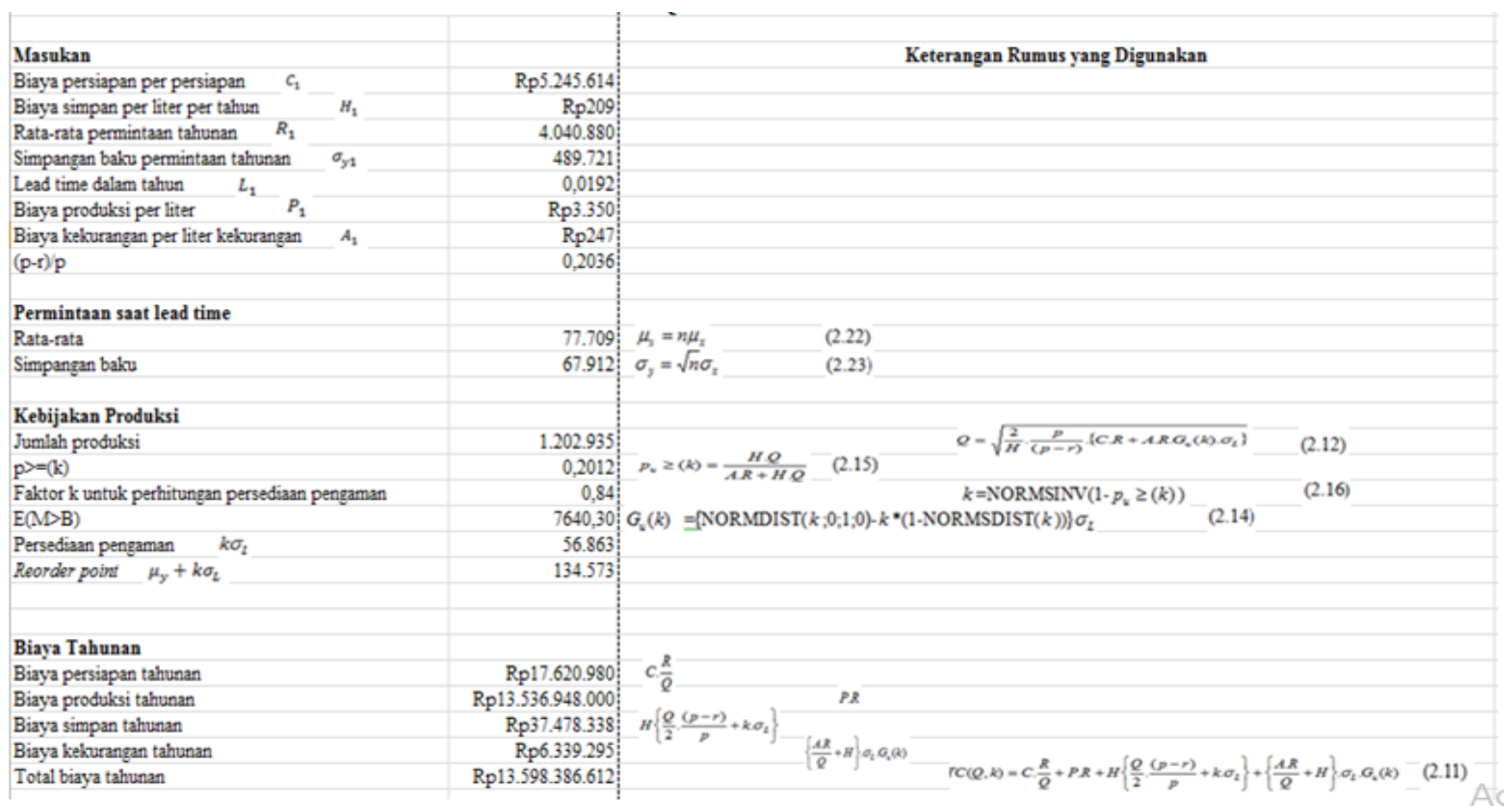

Tabel 3.3. Perhitungan Total Biaya Persediaan Tahunan untuk produk ke-2.

Model EMQ Stochastic untuk Produk ke-2 


\begin{tabular}{|c|c|c|}
\hline Masukan & & Keterangan Rumus yang Digunakan \\
\hline Biaya persiapan per persiapan $\quad C_{2}$ & Rp10.491.228 & \\
\hline Biaya simpan per liter per tahun & Rp418 & \\
\hline Rata-rata permintaan tahunan $\quad R_{2}$ & 3.434 .748 & \\
\hline Simpangan baku permintaan tahunan $\quad \sigma_{y 2}$ & 416.263 & \\
\hline Lead time dalam tahun $\quad L_{2}$ & 0,0385 & \\
\hline Biaya produksi per liter $\quad P_{2}$ & Rp6.700 & \\
\hline Biaya kekurangan per liter kekurangan $\quad A_{2}$ & Rp494 & \\
\hline$(\mathrm{p}-\mathrm{r}) \mathrm{p}$ & 0,6760 & \\
\hline \multicolumn{3}{|l|}{ Permintaan saat lead time } \\
\hline Rata-rata & Rp66.053 & $\mu_{3}=n \mu_{x} \quad(2.22)$ \\
\hline Simpangan baku & Rp57.725 & $\sigma_{y}=\sqrt{n} \sigma_{x} \quad(2.23)$ \\
\hline \multicolumn{3}{|l|}{ Kebijakan Produksi } \\
\hline Jumlah produksi & 505.039 & $Q=\sqrt{\frac{2}{H} \cdot \frac{p}{(p-r)} \cdot\left(C \cdot R+A R G_{0}(k) \cdot \sigma_{L}\right)}$ \\
\hline $\mathrm{p}>=(\mathrm{k})$ & 0,1107 & $P_{v} \geq(k)=\frac{H Q}{A R+H Q}$ \\
\hline Faktor $k$ untuk perhitungan persediaan pengaman & 1,2231 & $k=\operatorname{NORMSINV}\left(1-p_{.} \geq(k)\right) \quad(2.16)$ \\
\hline $\mathrm{E}(\mathrm{M}>\mathrm{B})$ & 3.088 & $G_{v}(k) \equiv\left\{\operatorname{NORMDIST}(k ; 0 ; 1 ; 0)-k^{*}(1-\operatorname{NORMSDIST}(k))\right\} \sigma_{z}$ \\
\hline Persediaan pengaman $\quad k \sigma_{2}$ & 178.265 .144 & \\
\hline Reorder point $\mu_{y}+k \sigma_{t}$ & 178.331 .197 & \\
\hline \multicolumn{3}{|l|}{ Biaya Tahunan } \\
\hline Biaya persiapan tahunan & Rp71.350.382 & $c \cdot \frac{R}{0}$ \\
\hline Biaya produksi tahunan & Rp23.012.811.600 & $Q P R$ \\
\hline Biaya simpan tahunan & $R p 249.615 .527$ & $H\left\{\frac{Q}{2} \cdot \frac{(p-r)}{p}+k \sigma_{t}\right\}$ \\
\hline Biaya kekurangan tahunan & Rp10.375.270 & 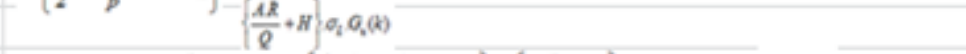 \\
\hline Total biaya tahunan & $\operatorname{Rp} 23.344 .152 .779$ & $r C(Q, k)=C \cdot \frac{R}{Q}+P R+H\left\{\frac{Q}{2}, \frac{(p-r)}{P}+k \sigma_{L}\right\}+\left\{\frac{A R}{Q}+H\right\} \sigma_{l} \sigma_{0}(k) \quad$ (2.11) \\
\hline
\end{tabular}




\section{Kesimpulan}

Model persediaan EMQ yang dengan produk ganda dan stochastik dapat diperoleh dengan menggabungkan antara model persediaan EOQ stochastic dengan model persediaan EMQ deterministic yang dilanjutkan dengan penambahan fungsi sigma untuk mendapatkan produk ganda. Total biaya persediaan tahunannya diperoleh dengan mengakumulasikan total biaya persediaan tahuanannya setiap produk, dari produk ke-i sampai dengan produk ke-n.

\section{DAFTAR PUSTAKA}

[1] Ayres Jr,F., Mendelson,E., Reece,G., Schaum's Outline of Therory and Problems of Differential and Integral Calculus, $3^{\text {rd }}$ ed in SI Units, McGraw-Hill Book Company, 1992.

[2] Elsayed,E.A., Boucher,T.O., Analysis and Control of Production Systems, $2^{\text {nd }}$, Prentice-Hall International., 1994.

[3] Hsu,H.P., Schaum's Outline of Theory and Problems of Probability, Random Variables, and Random Processes, McGraw-Hill, 1997

[4] Johnson,L.A., Montgomery,D.C, Operations Research in Production Planning, Scheduling, and Inventory Control, John Wiley \& Sons, Inc., 1974.

[5] Moore,J.H., Weatherford,L.R., Decision Modeling with Microsoft Excel, $6^{\text {th }}$ ed, Prentice Hall Upper Saddle River, New Jersey, 2001.

[6] Silver,E.A., Pyke,D.F., Peterson,R., Inventory Management and Production Planning and Scheduling, $3^{\text {rd }}$ ed, John Wiley \& Sons, 1998.

[7] Sipper,D., Bulfin, Jr,R.L., Production: Planning, Control, and Integration, The MacGraw-Hill Companies, Inc, 1998.

[8] Smith,B.S., Computer-Based Production and Inventory Control, Prentice-Hall International, Inc, 1989. 